\title{
Anti-malarial drug effects on parasite dynamics in vivax malaria
}

\author{
Nicholas J. White ${ }^{1,2^{*}}$ (1)
}

\begin{abstract}
Relapses of Plasmodium vivax malaria are prevented by 8-aminoquinolines. If hypnozoites survive, then the subsequent blood stage infections in early relapses ( $<2$ months) are suppressed by the slowly eliminated anti-malarial drugs used to treat the blood stage infection (chloroquine, artemisinin combination treatments), but they are not usually eliminated. The 8-aminoquinolines have significant blood stage activity which contributes to therapeutic responses. The latent interval from primary infection to early relapse depends on the number of activatable hypnozoites, the dose of anti-malarial, its pharmacokinetic properties, the level of resistance (minimum inhibitory concentration) and immunity. The dose-response relationship for radical curative efficacy of primaquine and tafenoquine is steep over the total dose range from 1.5 to $5 \mathrm{mg}$ base $/ \mathrm{kg}$ which may explain the poor efficacy of tafenoquine at the currently recommended dose.
\end{abstract}

\section{Background}

Relapse of malaria refers to a recurrence of the infection derived from dormant liver stage parasites called hypnozoites. Relapses occur in infections with Plasmodium vivax and the two Plasmodium ovale sibling species, and in several primate malarias-notably Plasmodium cynomolgi, which is the usual animal model of vivax malaria. In tropical areas of Asia and South America, where $P$. vivax is often the dominant malaria parasite, relapses occur at frequent intervals. They are a major cause of morbidity, particularly in young children, and in areas of higher transmission, they contribute to anaemia and childhood mortality $[1,2]$.

Relapse is a major impediment to malaria elimination because the only drugs that can prevent them and thereby provide "radical cure" are the 8-aminoquinolines, and they are under used. This class of drugs causes oxidant haemolysis in patients with glucose-6-phosphate dehydrogenase deficiency (G6PDd) which is very common in

\footnotetext{
*Correspondence: nickw@tropmedres.ac

${ }^{1}$ Mahidol-Oxford Tropical Medicine Research Unit, Faculty of Tropical Medicine, Mahidol University, Bangkok 10400, Thailand

Full list of author information is available at the end of the article
}

tropical areas (X-linked; gene frequencies average 8-10\% but can be as high as 35\%) [3]. G6PD testing is often unavailable, so prescribers are commonly reluctant to risk haemolysis in order to prevent relapse.

Radical cure (to prevent relapses) needs to be used more widely, but questions remain on optimum dosing. Evaluating relapse prevention is compromised by the difficulty in differentiating recrudescence (recurrence of the blood stage infection), relapse and reinfection. This is because relapses can be with $P$. vivax parasites which are from the incident infection, and thus genetically identical or closely related, or can arise from previously acquired hypnozoites which are genetically unrelated to the incident infection $[4,5]$. The reduction in the probability of relapse (radical cure efficacy) depends on the dose of 8 -aminoquinoline (and the quality and bioavailability of the formulation) and the number of activatable hypnozoites in the liver (and thus the intensity of previous malaria exposure). Other important determinants are the degree of immunity and, for primaquine, the presence of lossof function cytochrome $\mathrm{P} 450$ genetic polymorphisms. This is because cytochrome P450 (particularly 2D6) is responsible for primaquine bioactivation. The exact mode of action of the 8-aminoquinolines is not known 
but involves generation of reactive oxidative intermediates. Primaquine is metabolized rapidly (elimination halflife $\sim 5 \mathrm{~h}$ ) via monoamine oxidase to a biologically inert metabolite-carboxyprimaquine-and, through a separate pathway, to several active hydroxylated metabolites mainly via CYP 2D6 [6]. Based on studies of the gametocytocidal activity of primaquine in P. falciparum (which is a reasonable pharmacodynamic proxy for the hypnozoitocidal activity) the proposed sequence of events is as follows [7]. The unstable hydroxylated metabolites of primaquine are oxidized to quinoneimines generating local hydrogen peroxide-which is parasiticidal. The quinoneimines in turn are substrates for cytochrome P450 NADPH:oxidoreductase (POR or CPR) resulting in more hydrogen peroxide accumulation and augmenting the parasiticidal effect. Synergy between the 8-aminoquinoline and the concomitant 4-aminoquinoline (or structurally related compounds) used to treat the blood stage infection has also been shown to contribute to radical curative efficacy. Slowly eliminated anti-malarials used in the treatment of the acute malaria infection are also a major determinant of the interval to patent relapse as, following release of parasites from the liver into the blood approximately 2 weeks later, residual levels of these drugs reduce subsequent asexual blood stage multiplication (Fig. 1). This review assesses the effects of anti-malarial drugs on $P$. vivax parasite dynamics and therapeutic responses in early relapse.

\section{The latent period}

This is the interval between the initial patent infection and the subsequent relapse (which is usually confirmed by microscopy). The latent period for the tropical, frequently relapsing, "strains" (represented by the "Chesson" strain) is approximately 3 weeks if a rapidly eliminated anti-malarial is used for primary treatment (i.e. artesunate or quinine) [29-31]. It is variably longer if slowly eliminated anti-malarial drugs are used for the reasons described above (i.e. suppression of blood stage multiplication; Fig. 1). In temperate regions $P$. vivax may have a long incubation period of 8-9 months or a similarly long interval between the primary illness and the relapse [31]. Long latency is an important consideration in assessing radical curative efficacy, but is unaffected by residual drug levels from the primary infection treatment. The 3-week latency for the frequent relapsing $P$. vivax "tropical strains" which predominate today suggests that their hypnozoites begin to divide approximately 1 week after the onset of the primary infection illness (i.e. 3 weeks after the preceding sporozoites were inoculated) (Fig. 2). This assumes that once the hypnozoite or hypnozoites awaken and intrahepatocyte cell division starts then the rate of multiplication within the developing schizonts is

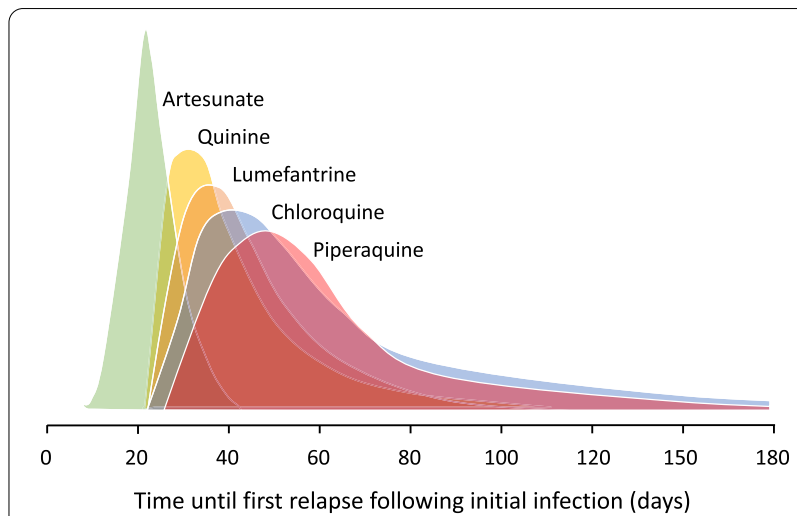

Fig. 1 The temporal distribution of first relapses in tropical P. vivax infections treated with different anti-malarial drugs. Artesunate was given for 5 or 7 days. The quinine interval was derived from studies in which quinine was given for 14 days. The interval is shorter after currently recommended 7-day quinine regimens. The other drugs are given in 3 day regimens. Lumefantrine and piperaquine are the slowly eliminated components of artemisinin-based combinations. This temporal pattern of first relapses reflects the elimination kinetics of the different drugs and thus the duration of suppression of asexual stage multiplication in the relapsing infection [8-28]

similar to that in the primary (incident) infection. Thus, the interval from acute illness to maturity of the hypnozoite derived relapse hepatic schizonts is approximately 2 weeks. The number of merozoites liberated into the blood by a single mature hepatic schizont of $P$. vivax is approximately 10,000 [32]. Once liberated, asexual multiplication of the blood stage infection in the absence of drugs or effective immunity is approximately $8-10$ fold every $\sim 48 \mathrm{~h}$. As a result, in adults (blood volume approximately $5 \mathrm{~L}$ ), if only one schizont has ruptured then patent parasitaemias $(>50 / \mathrm{uL})$ are reached in four asexual cycles (8 days) [33]. This represents four multiplication steps from $10^{4}$ to $10^{8}$ asexual parasites. The interval to patency (microscopy detectable parasitaemia) shortens with smaller blood volumes (i.e. children) and larger numbers of activated hypnozoites (e.g. the interval would be 6 days if 10 hypnozoites were activated) [34-36]. The $\sim 50 / \mathrm{uL}$ limit of detection for routine microscopy and the latest rapid diagnostic tests (RDTs) is close to the pyrogenic density in $P$. vivax infections $[37,38]$.

In summary the latent period depends on several factors which include.

a. Blood stage immunity against the asexual parasites.

b. Pyrogenic density.

c. Body size and thus blood volume (i.e. age).

d. Concentrations and inhibitory activity of blood stage anti-malarial drugs.

e. The number of surviving activated hypnozoites. 
Early P. vivax relapse

Liver stage multiplication

Blood stage multiplication

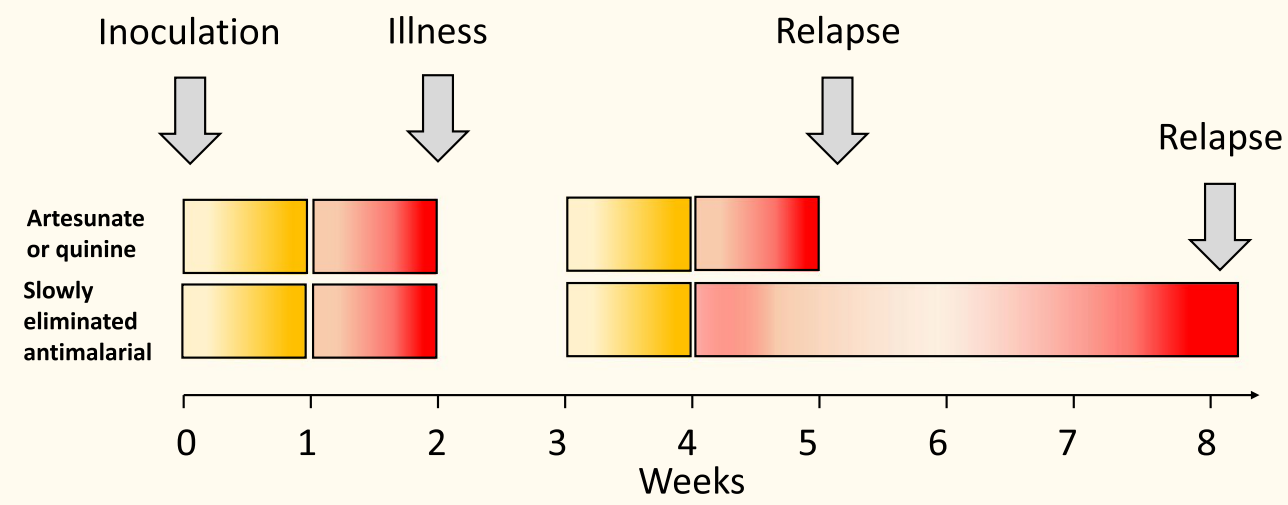

Fig. 2 Usual intervals from initial sporozoite inoculation to primary illness and then first relapse in tropical P. vivax. This assumes multiplication in the developing hepatic schizonts is similar in the primary infection and relapse. Relapse patency is delayed after treatment with slowly eliminated anti-malarials because of blood stage multiplication inhibition from residual drug levels

\section{The hypnozoite burden}

Much remains to be learned about hypnozoite biology, but clinical and experimental studies strongly suggest that in malaria endemic areas, individuals often have a few dormant, but activatable, hypnozoites in their livers [31]. If the proportion of acute falciparum malaria infections which are followed shortly afterwards by a P. vivax infection (with an interval corresponding to the latent period) is a guide, this suggests that between $20 \%$ and $60 \%$ of endemic area residents have pre-existing activatable hypnozoites [39-42]. This explains why relapses in endemic regions are often with $P$. vivax parasites which are genetically unrelated to those causing the index infection $[4,5,31]$. It may, therefore, be inferred that in endemic areas there is a quasi-steady state in which individuals acquire hypnozoites, usually with a blood stage infection (which may or may not be symptomatic), and later lose these hypnozoites by activation or hepatocyte apoptosis. The hypnozoite burden at any time depends on the previous intensity (force) of infection and the individual's exposure to infectious mosquito bites. In the majority of $P$. vivax endemic areas outside Oceania the average entomological inoculation rate is low $(\sim 1$ infectious bite per person per year) although, even in these low transmission settings, there are focal areas ("hot spots") of much higher transmission [43]. It has been estimated that approximately half the inoculated sporozoites of "Chesson strain" $P$. vivax are destined to become hypnozoites [44]. As the median sporozoite inoculum from an infected mosquito bite is estimated to be 6-10 sporozoites, each inoculum would give a median of 3-5 hypnozoites [45-47].

Intense exposures in areas of high transmission (e.g. on the island of New Guinea) result in heavy hypnozoite burdens and, in non-immune visitors, these cause multiple symptomatic relapses [48, 49], but in most other areas of the world $P$. vivax transmission is much lower. There are also substantial geographic differences in the proportions of $P$. vivax infections which relapse. Overall, in endemic areas the majority of relapses are asymptomatic as older children and adults acquire disease controlling immunity ("premunition") [50, 51]. In low transmission regions between $20 \%$ and $85 \%$ of patients presenting with acute vivax malaria (and not receiving radical treatment with primaquine) will have no detectable relapse of $P$. vivax $[31,52,53]$. This strongly suggests that the number of activatable hypnozoites is low (i.e. the individual probability that a hypnozoite can be activated is low) [31]. The more hypnozoites that are activated, the shorter is the latent period. This was demonstrated clearly in Leon Schmidt's classic investigations of $P$. cynomolgi, the closest animal "model" of vivax malaria $[36,54-56]$. There are two reasons for this: first, the starting number of merozoites liberated by the hepatic schizonts is larger, and second is because there is a distribution of latent periods, and it is the progeny of the first schizont 
to liberate merozoites, that will usually reach patency first [31].

\section{Blood stage multiplication}

Blood stage multiplication of the relapsing infection is constrained by "immunity" (if there is any) to the relapsing parasites, host factors such G6PD deficiency, and by the blood concentrations and activity of anti-malarial drugs [56-58].

\section{Chloroquine}

Chloroquine is the most widely used treatment of vivax malaria. Chloroquine has complex pharmacokinetic properties characterized by an enormous apparent volume of distribution and very slow elimination [59]. However, by 2 weeks after starting the 3-day anti-malarial treatment, when relapse merozoites first appear from the liver, whole blood chloroquine concentrations have fallen to $\sim 150 \mathrm{ng} / \mathrm{mL}$ (although there is up to sixfold inter-individual variation) [59-61] (Fig. 3). These concentrations are still sufficient to inhibit growth of $P$. vivax-unless there is high level resistance. As a result, unless chloroquine concentrations in the blood are unusually low, asexual parasite densities of the first relapse will fall initially after emerging from the liver until the chloroquine concentrations fall to below the minimum inhibitory concentration (MIC). Thereafter the parasite densities rise again and will reach patency several weeks later (the first relapses after chloroquine treatment generally become patent around 6 to 7 weeks after the initial treatment-although there is significant inter-individual variation) $[8-17,57,58,61,62]$ (Figs. 2 and 3 ). The interval to the first detected recurrence depends on the exposure of the drug (and thus the dose of chloroquine administered) [52, 58]. As a result, the first evidence of chloroquine resistance is less inhibition of blood stage growth and earlier patency of the first relapse [57]. For chloroquine, the appearance of relapses within 35 days of starting chloroquine together with a whole blood chloroquine + desethychloroquine

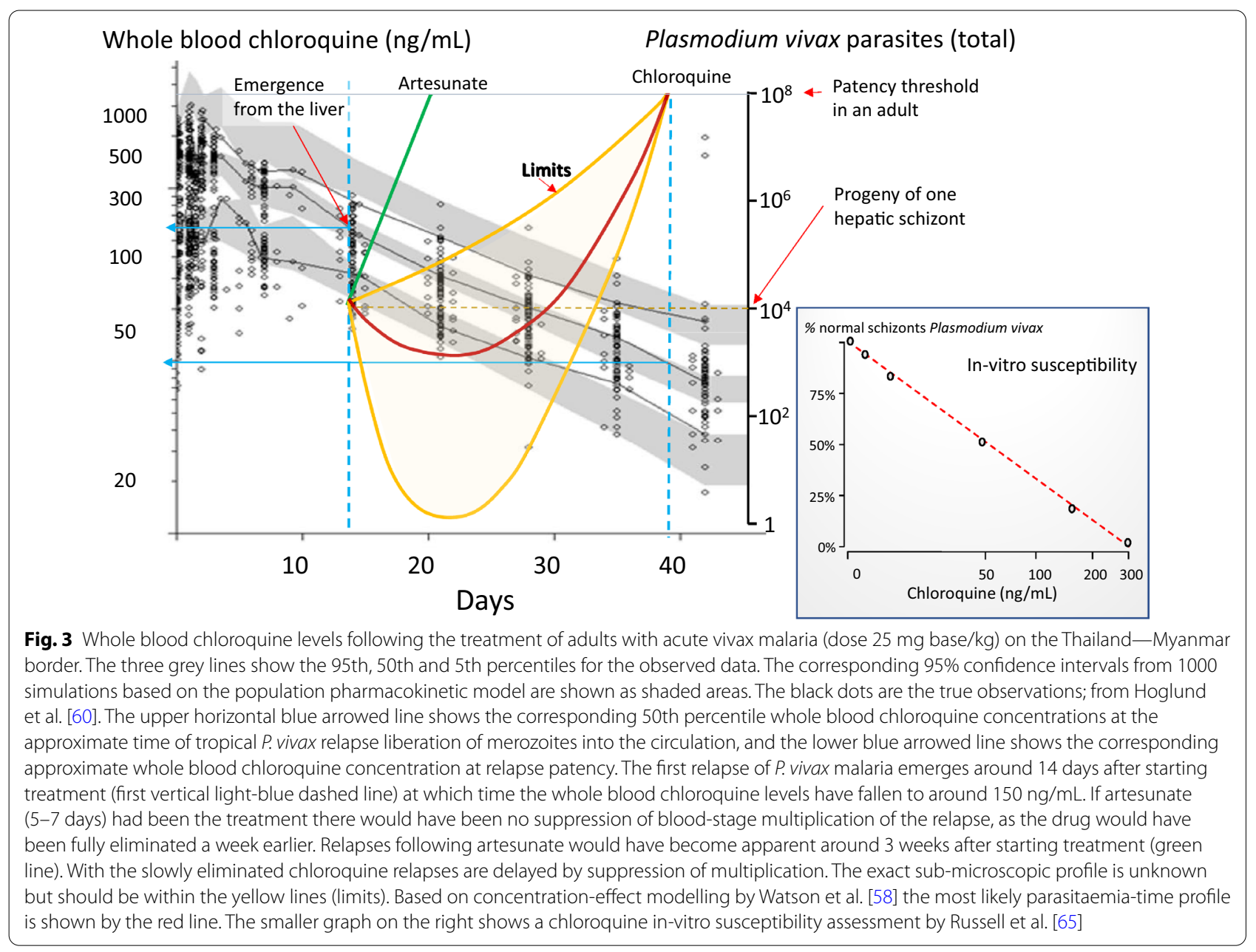


(combined) concentration over $100 \mathrm{ng} / \mathrm{mL}$ has been proposed as an indicator of resistance $[63,64]$.

In summary, the first relapse following chloroquine treatment of vivax malaria in tropical areas has probably persisted in the blood for 3-5 weeks before becoming patent. In contrast, following treatment with rapidly eliminated drugs such as artesunate or quinine for 5-7 days, there is no suppression of asexual stage multiplication and the first relapse becomes patent approximately one week after leaving the liver $[16,18,19,30]$ (Figs. 2 and 3).

\section{ACT partner drugs}

Lumefantrine is the most rapidly eliminated of the ACT partner drugs and so suppresses $P$. vivax relapses for a shorter period $[14,20,21]$ than the more slowly eliminated piperaquine, mefloquine, desethylamodiaquine, pyronaridine or chloroquine [8-17, 20-27, 61, 62]. Cumulative relapse rates are only slightly lower with the slowly eliminated anti-malarials [16, 28, 31]. This suggests that few relapses are eliminated by the residual anti-malarial drug concentrations. Nevertheless, delaying relapse may still have some therapeutic advantages such as allowing more time for recovery from illness and anaemia $[2,22,66]$. It is important therefore to have sufficient follow-up to capture relapses when comparing two treatments with different elimination kinetics, otherwise the more slowly eliminated drug will appear to have superior recurrence preventing efficacy. For drugs such as chloroquine, desethylamodiaquine, piperaquine, mefloquine and pyronaridine, four months is probably the minimum duration of follow-up (Fig. 4).

\section{Radical cure}

Relapses are prevented by the hypnozoitocidal effects of the 8-aminoquinolines [70, 71]. These are the only available drugs which kill hypnozoites [71]. Radical cure efficacy is dependent on the total dose administered [52, 71, 72] (Fig. 5) and the number of activatable hypnozoites.

A simple model is proposed in which the number of activatable hypnozoites follows a Poisson distribution with parameter $\lambda$ (the mean number of activatable hypnozoites). If a drug exposure results in a probability $\mathbf{p}$ of "killing" each hypnozoite independently, then the probability of the binary outcome of whether relapse occurs (defined as the probability that at least one hypnozoite remains) or not increases as a function of the mean number of activatable hypnozoites $(\lambda)$.

Under this Poisson-binomial model, the proportion of patients with at least 1 hypnozoite left after radical drug treatment.

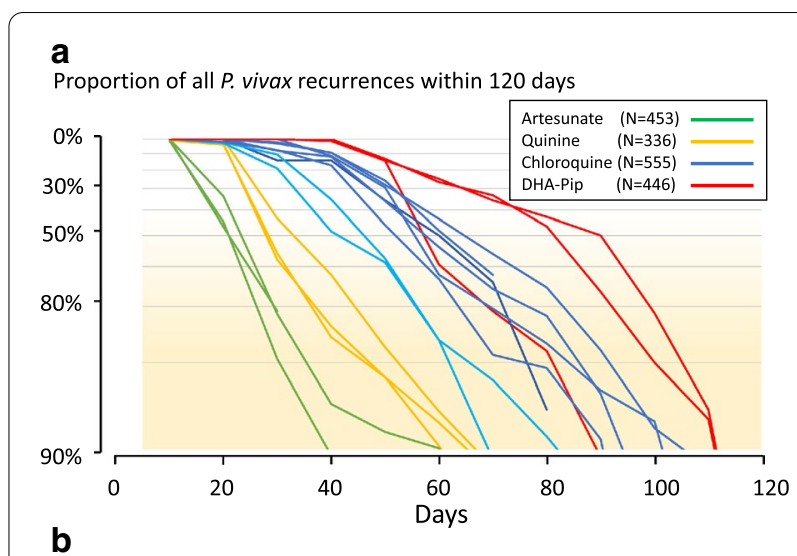

Proportion of all $P$. vivax recurrences within 120 days

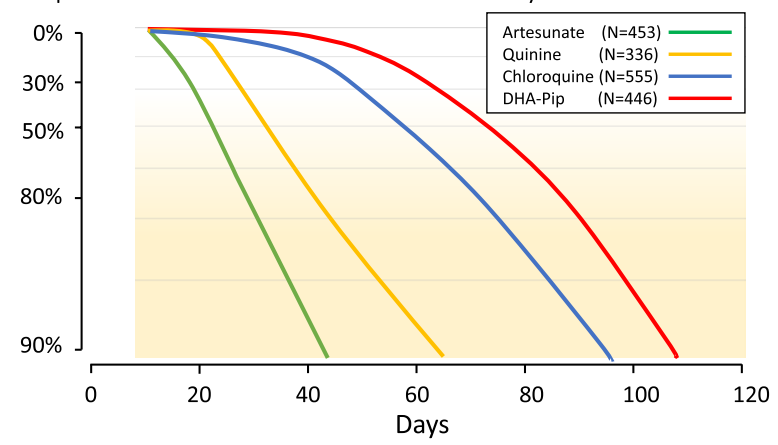

Fig. 4 Recurrence rates following the treatment of acute P. vivax malaria in trials with different anti-malarial drugs, but without 8-aminoquinolines, in which there was frequent assessment $[8-16,18-22,24,25,28,30,35,61,67-69]$. The percentages are the proportions of all recurrences observed by 120 days over time. They show more rapid reappearance (presumed relapse) of vivax malaria with more rapidly eliminated drugs. Left (a): Individual trials (light blue shows two trials from the Thailand-Myanmar border where there is low grade chloroquine resistance, darker blue lines are from trials conducted in areas where $P$. vivax is generally more chloroquine sensitive). Right (b): average profiles

$$
\begin{aligned}
& =\text { proportion relapsing. } \\
& =1-\left(\mathrm{e}^{-\lambda} / \mathrm{e}^{-\lambda \mathrm{p}}\right) \\
& =1-\mathrm{e}^{-\lambda(1-\mathrm{p})}
\end{aligned}
$$

Figure 6 shows this relationship for different per hypnozoite drug efficacies and illustrates how the observed efficacy is strongly dependent on the latent hypnozoite load.

If relapses do occur after a primaquine radical cure regimen has been given, then they are not markedly delayed. This suggests that subsequent hepatic schizont development is not retarded in the surviving hypnozoites. Thus, relapses which do occur following 8-aminoquinolines are likely to arise from few, and often a single hypnozoite (the exception being in individuals with CYP 2D6 loss of function polymorphisms who do not bioactivate the primaquine). There are some geographic differences 


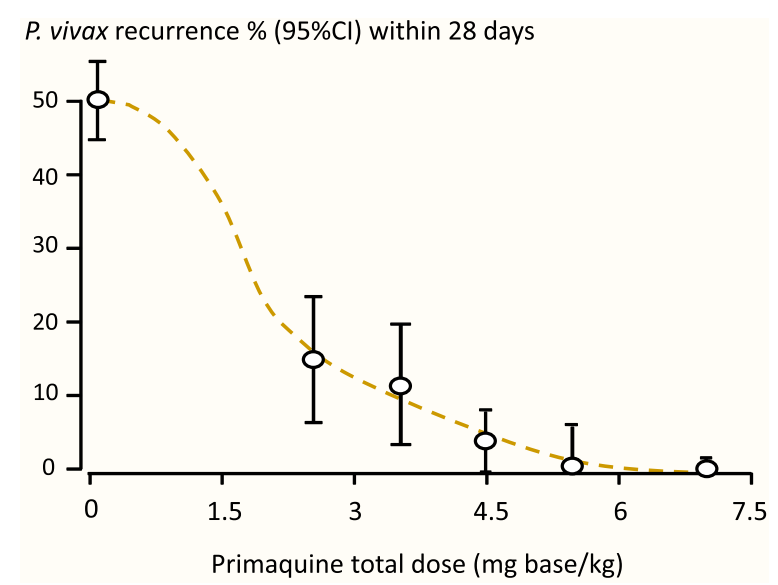

Fig. 5 Recurrence rates (presumed relapses) in hospitalized Thai adults with acute vivax malaria who were treated with artesunate for 5 or 7 days and given different durations of primaquine at $30 \mathrm{mg}$ (base)/day. From Pukrittayakamee et al. [72]

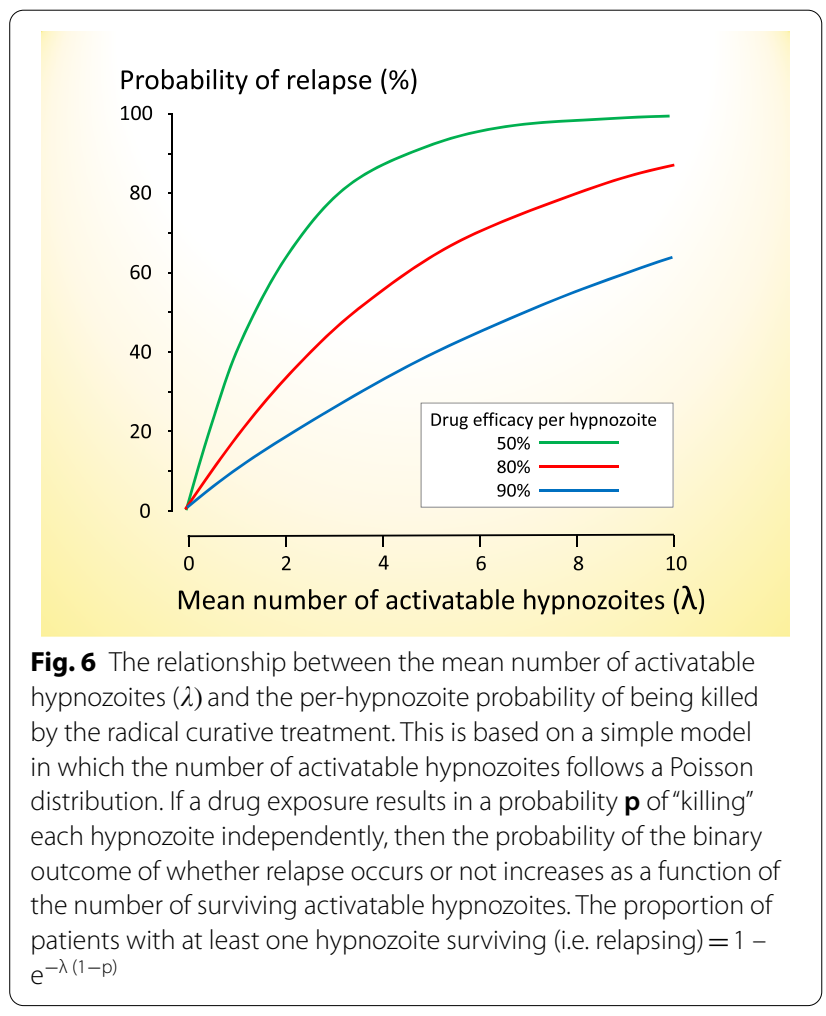

in susceptibility. The long latency "strains" (such as the Korean $P$. vivax which gave the currently recommended dose regimens of primaquine) are more sensitive [73, 74] and "strains" from Oceania (Chesson type) are considered to be intrinsically more resistant $[28-30,75]$. There is no evidence for acquired resistance in hypnozoitocidal activity [31]. However, acquired resistance to the asexual stage activity of these drugs has been demonstrated in clinical experiments [76]. The blood stage activity of primaquine against $P$. vivax is sufficient to cure the infection when given alone [72, 77]. The parasitological response to primaquine alone is slower than following treatment with chloroquine. Parasite clearance rates are similar to those observed with quinine treatment [56] (Fig. 7). This significant blood stage activity contributes to the overall blood stage therapeutic effect in combination with chloroquine or an $\mathrm{ACT}$, and therefore reduces the probability of recrudescence (as well as the hypnozoitocidal effect reducing relapse). There is evidence for synergy between the 8 -aminoquinolines and other quinoline anti-malarials in blood stage activity as well as in radical curative activity [78-80]. Highly chloroquine resistant $P$. vivax may still respond to chloroquine and primaquine because of primaquine's blood stage activity $[77,81]$. As described earlier, the similarity of the interval to first relapse, whether primaquine has been given or not, does suggest that hepatic schizont cell division is not affected in the progeny of the few hypnozoites that survive radical cure regimens.

\section{Assessing drug effects in vivax malaria Initial response}

The assessment of initial responses to drug treatment in vivax malaria is generally similar to that in falciparum malaria, but there are some important differences. First, parasite densities are lower in vivax malaria and very seldom exceed 100,000/uL [37]. Serial assessment of parasite densities to assess parasite clearance

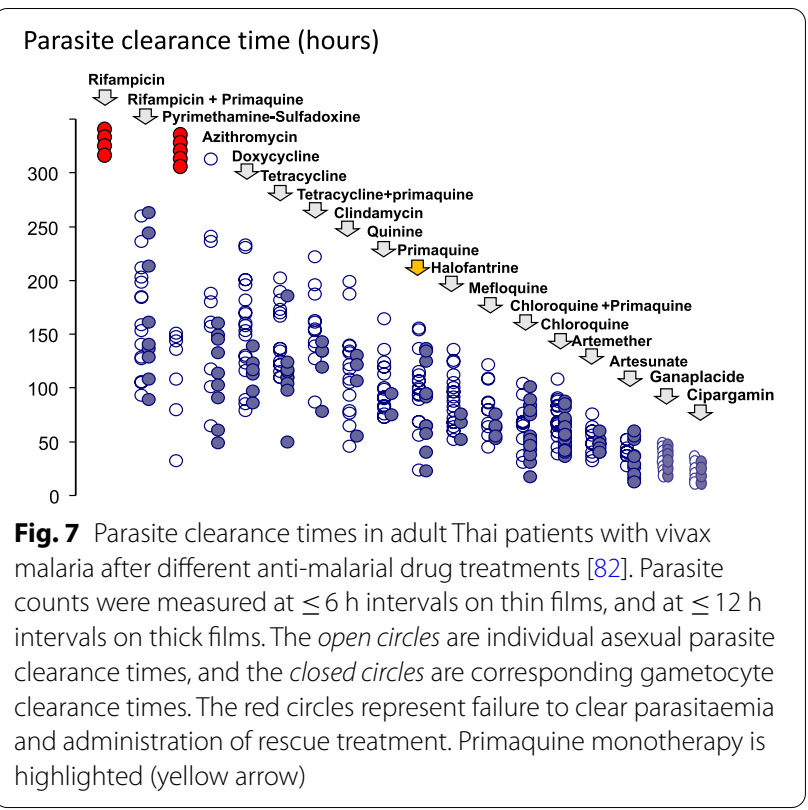


rates is therefore less accurate. Second, $P$. vivax does not cytoadhere appreciably (although it does accumulate markedly in the spleen [83]). This removes the major complexity of distinguishing drug effects from sequestration in assessing parasite density-time relationships. Third, persistent gametocytaemia is not a confounder as asexual stages of $P$. vivax are considered equally susceptible to the anti-malarial drugs [82] (Fig. 7). Thus, slowing of asexual and sexual stage clearance is a measure of drug resistance, and is a useful indicator of high-level resistance, but it is insensitive at lower levels of resistance. For slowly eliminated drugs, such as chloroquine, which have multiexponential elimination concentration profiles, the blood concentrations in the first few days of treatment are substantially higher than those 2 weeks later when relapse merozoites first emerge from the liver (Fig. 3). These relatively high concentrations retain full activity $\left(\mathrm{E}_{\max }\right)$ against moderately resistant $P$. vivax. Taylor et al. studied chloroquine resistant $P$. vivax in Papua over 20 years ago; despite a $71 \%$ treatment failure rate within 28 days, the mean $(95 \% \mathrm{CI})$ parasite clearance time was 2.4 days (1.9 to 2.9 days) i.e. similar to that elsewhere in sensitive $P$. vivax infections [67]. Thus, slowing of parasite clearance for chloroquine (and for other drugs with similar pharmacokinetic properties) is an insensitive measure of developing resistance.

\section{Radical cure}

Unless there is such high-grade resistance that total asexual parasite burdens 2 weeks after starting treatment (e.g. with chloroquine) exceed 10,000 (the approximate number of merozoite progeny of one activated hypnozoite) then relapses will generally precede recrudescences (if there are any). High level chloroquine resistance, where recrudescence predominates, is seen currently only on the island of Borneo, in Indonesia and in Oceania [25, 63, 64, 67-69] (Fig. 8). The clinical manifestation of worsening chloroquine resistance will therefore be earlier and earlier recurrences (with an increasing proportion of parasites being genetically similar to the primary infection as recrudescences comprise an increasing proportion of recurrences). Even if the recurrence is caused by a new infection, it still reflects resistance as only resistant parasites can grow to reach patent parasitaemias through residual drug concentrations (e.g. 2-4 weeks after chloroquine treatment).

Most published clinical trials describing radical curative efficacy report cumulative recurrence rates after different drug regimens (Fig. 9). As explained, drug exposures, parasite numbers and levels of resistance all contribute to the interval to relapse. The first relapses in clinical trials will therefore be in patients with higher numbers of hepatic schizonts, more resistant parasites (referring to blood stage resistance) and lower drug levels. The net result is a skewed distribution of intervals to

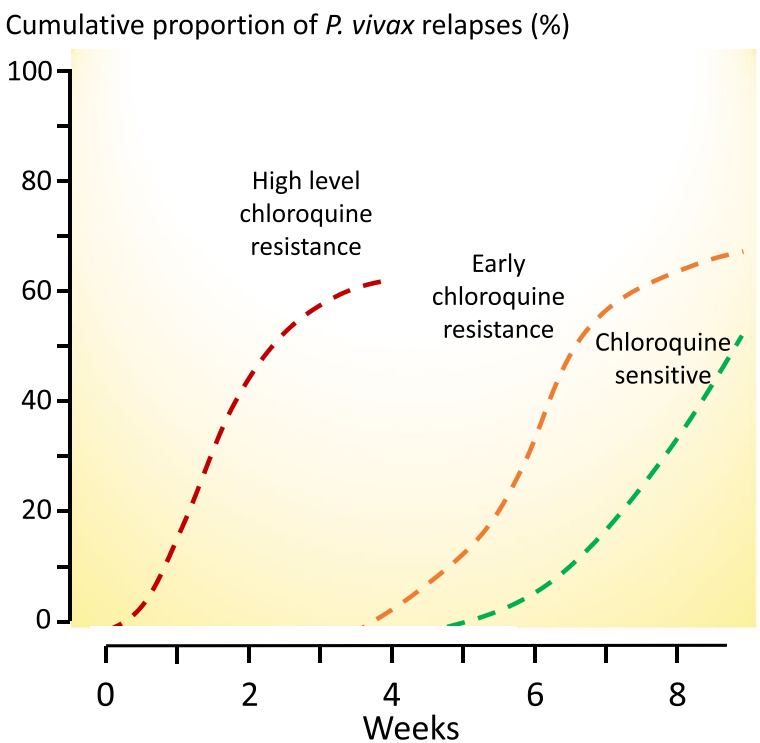

Cumulative proportion of $P$. vivax relapses (\%)

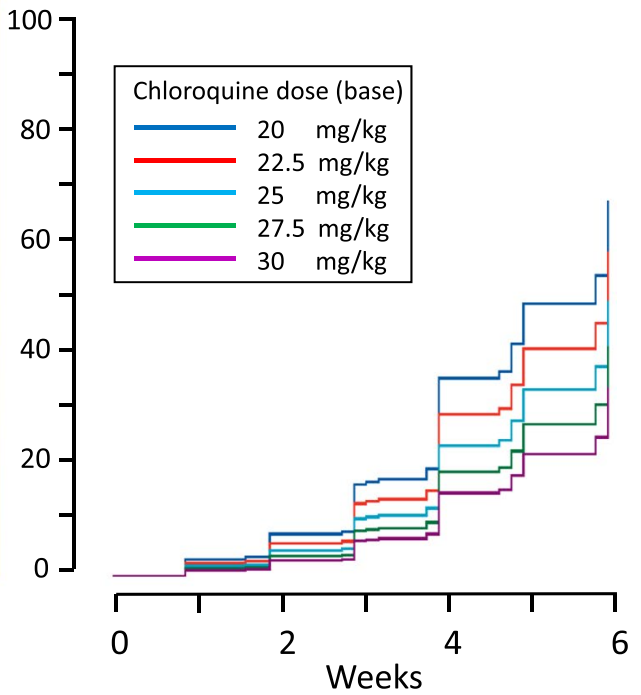

Fig. 8 Left:Temporal profiles of $P$. vivax recurrence at different levels of chloroquine resistance. At high levels of resistance (as seen currently in Indonesia and Papua New Guinea) early recrudescence dominates (red dashed line). At lower levels of resistance (as seen currently on the ThailandMyanmar border) the relapses appear earlier than previously, and a few appear within 28 days (orange dashed line). In fully sensitive infections no relapses appear within 4 weeks, and very few occur before 6 weeks (green dashed line). Right: The effect of chloroquine dose (and thus exposure) on the time to $P$. vivax recurrence; from Commons et al. [52] 


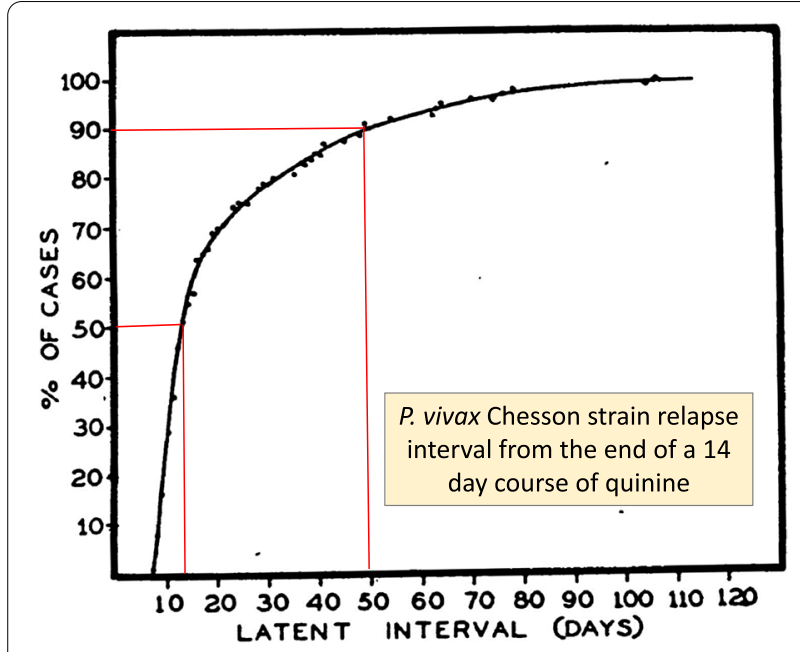

Fig. 9 Cumulative proportion of P. vivax relapses in volunteers infected with Chesson strain P. vivax from Alving et al. during evaluations of different 8-aminoquinolines for radical cure [29]. The latent interval was calculated from the end of a 14-day course of quinine ( $2 \mathrm{~g} /$ day of either the sulfate or hydrochloride salts in six divided doses) to treat the primary infection

relapse, with later modal intervals following treatments with more slowly eliminated anti-malarials (Fig. 1). If patients or volunteers are studied outside the malaria transmission area then reinfection is not possible, so recurrences must be either relapses or recrudescences. Within the endemic area reinfection occurs and the proportion of recurrences which are not relapses (i.e. reinfections) rises with time, and is strongly influenced by the rainy season in low transmission settings. With longer follow-up recurrent infections comprise an increasing proportion of cases. This dilutes the end point in comparative trials. The progressive loss of specificity reduces statistical power and compromises non-inferiority comparisons. The more intense the transmission (reinfection probability), the more rapid is the dilution. Time-toevent information and parasite genotyping allows a probabilistic discrimination between relapse and reinfection which improves the power and precision of therapeutic assessments [84]. However, occasional late relapses (many months later) do still occur, even with frequent relapsing $P$. vivax, as Coatney showed unequivocally in volunteers who received single infected mosquito bites [35]. But the large majority of recurrences which occur within a few months are relapses, even in higher transmission settings, - and these are prevented by sufficient doses of 8 -aminoquinolines $[71,80]$. What then is the optimum duration of follow-up to assess radical cure efficacy? This depends first on whether long-latency $P$. vivax is prevalent (in which case 1 year is minimum), and then on the drugs used. In general, the majority of early

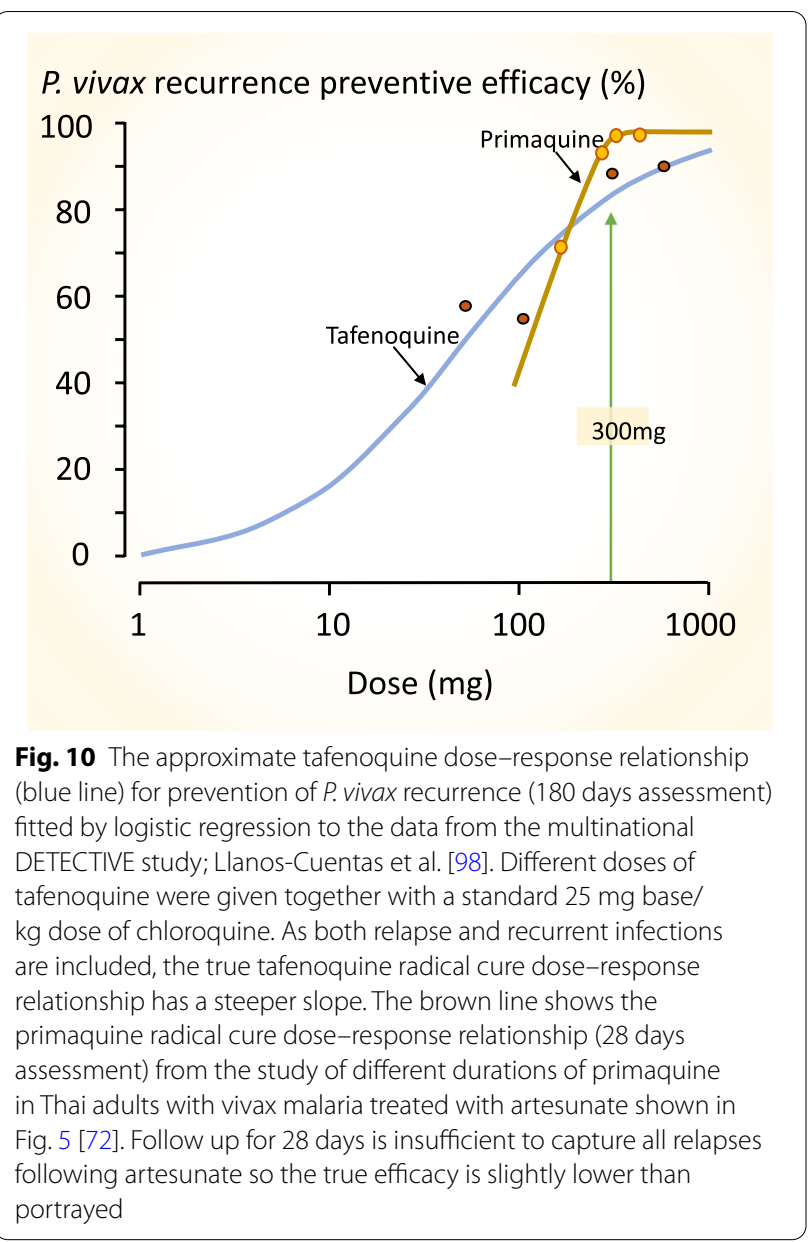

relapses occur within 2 months, most have occurred within 4 months, and there are relatively few incident relapses thereafter. Thus, 6 months is a reasonably conservative duration of follow-up for chemotherapy studies of frequent relapse $P$. vivax and 4 months will still provide the majority of comparative information.

The radical curative efficacy of primaquine has been reviewed extensively [70]. The total dose of $3.5 \mathrm{mg}$ base/ $\mathrm{kg}$ (i.e. $0.25 \mathrm{mg} / \mathrm{kg} /$ day for 14 days or $0.5 \mathrm{mg} / \mathrm{kg} /$ day for 7 days) provides good efficacy everywhere except in SouthEast Asia and Oceania where a higher dose is needed (i.e. $0.5 \mathrm{mg} / \mathrm{kg} /$ day for 14 days or $1 \mathrm{mg} / \mathrm{kg} /$ day for 7 days). Despite this, most countries in these regions still recommend the lower dose. Recommended dosing in children has been the same as for adults, but exposures are lower in children (as is often the case for anti-malarial drugs) [85] so dose regimens might well need revising upwards in younger children. In patients who are G6PD deficient a weekly dose of $0.75 \mathrm{mg}$ base $/ \mathrm{kg}$ given for 8 weeks is recommended [71]. There are relatively few data to support the efficacy of this regimen and it is interesting to consider how it might work. By the time the first 
relapse merozoites leave the liver ( $\sim 14$ days) 3 doses (total $2.25 \mathrm{mg} / \mathrm{kg}$ has been taken). The first two doses (i.e. $1.5 \mathrm{mg} / \mathrm{kg}$ ) act on the pre-erythrocytic stage but, by extrapolation from the 8-aminoquinoline dose-finding studies, this is expected to have a partial effect at most on hypnozoite development. Thereafter, the subsequent six doses might well suppress the blood stage infection, but how they prevent relapse is unclear. G6PD deficiency itself protects against vivax malaria, so it is quite possible that the iatrogenic oxidant activity that leads to haemolysis also potentiates the blood stage anti-malarial effect. Thus, overall relapse preventive efficacy could be higher in G6PD deficient than in G6PD normal patients. More information is needed on the efficacy of this regimen as some countries have recommended the once weekly primaquine dose for all patients (because G6PD testing is unavailable).

\section{Assessing tafenoquine}

Tafenoquine (WR 238605; etaquine) is a synthetic analogue of primaquine ([2, 6-methoxy-4-methyl-5-(3-trifluoromethylphenoxy) primaquine, succinate] which is eliminated slowly. Tafenoquine was developed to provide comparable anti-malarial activity to primaquine, but over a much longer time period so that it could be given in a single dose [86-88]. In other words, it was designed to be more stable than primaquine.

Although tafenoquine has asexual stage activity invitro, the concentrations required for an anti-malarial effect are high by comparison with in-vivo exposures $[65,89,90]$. This suggests that tafenoquine requires invivo bioactivation, as does primaquine, although this is debated. Interestingly the CYP 2D6 intermediate loss of function polymorphisms, which are associated with impaired radical curative activity of primaquine, do not seem to affect the efficacy of tafenoquine-although the numbers studied were small [91, 92]. This may reflect a large difference in activation rates as the rapidly metabolized primaquine has a shorter period in-vivo for each dose in which to generate bioactive intermediates. Assessing liver stage activities ex-vivo in cultured hepatocytes is more representative of in-vivo activity as the cultured hepatocytes can bioactivate the 8-aminoquinolines [93, 94]. The slow elimination of tafenoquine means that, if relapses do still occur, then the blood stage multiplication of the first relapse is reduced as, on emergence from the liver, it encounters suppressive concentrations of tafenoquine. This delays the time to relapse patency [95-97]. Thus, relapses which follow tafenoquine are delayed both because hypnozoite numbers are reduced and, for the progeny of those hypnozoites which survive, subsequent asexual stage multiplication is inhibited by the slowly eliminated anti-malarials. Tafenoquine and chloroquine are synergistic both in liver and blood stage activities, but the degree to which this contributes to overall efficacy is uncertain.

Dose finding studies for tafenoquine show a clear dose-response relationship up to single adult doses of

\section{P. vivax recurrence preventive efficacy (\%)}

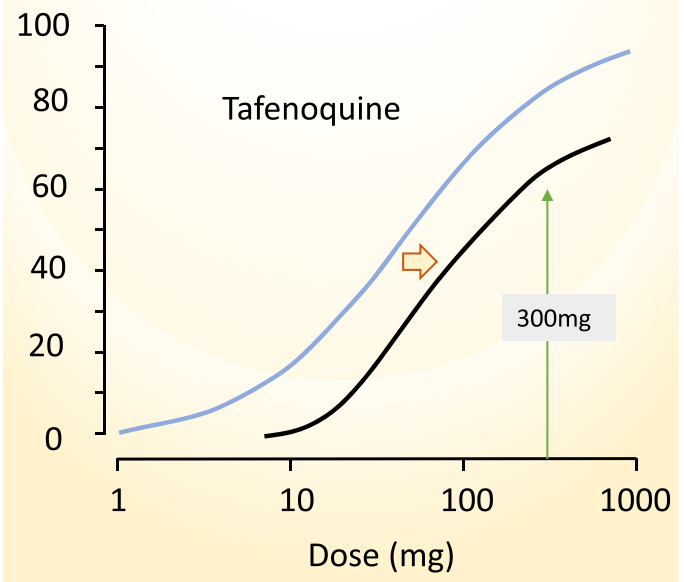

\section{P. vivax recurrence preventive efficacy (\%)}

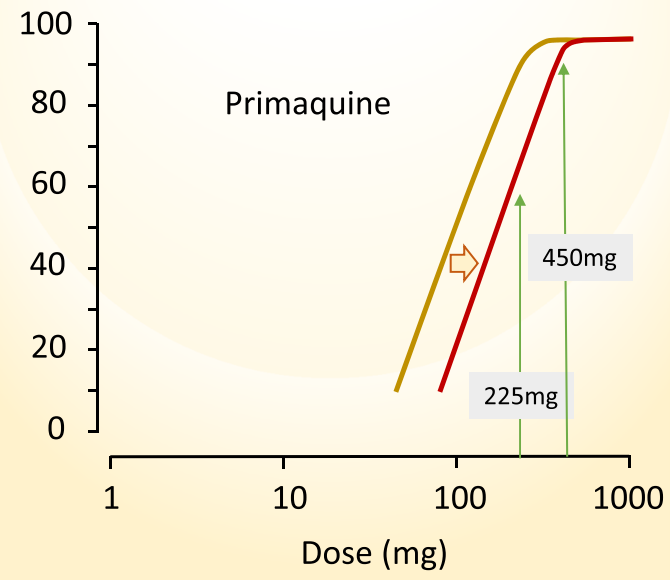

Fig. 11 (Left): An illustration of how shifts to the right in the dose- response relationship (such as would be associated with higher hypnozoite loads) are expected to have a significant effect on the radical curative efficacy of the tafenoquine $300 \mathrm{mg}$ adult dose (from Fig. 10). (Right): A similar illustration of the approximate dose-response relationship for primaquine in Southeast Asian P. vivax (from Fig. 10). This indicates that right shifts would give a greater reduction in radical curative efficacy of the widely used primaquine adult total dose of $210 \mathrm{mg}$ ( $15 \mathrm{mg}$ base/day for 2 weeks or $30 \mathrm{mg} /$ day for 1 week), than they would on the WHO recommended (but rarely followed) $420 \mathrm{mg}$ adult total dose (30 mg base/day for 2 weeks or $60 \mathrm{mg} /$ day for 1 week) 
$600 \mathrm{mg}$ [98]. In phase 3 pre-registration trials the currently recommended adult dose of $300 \mathrm{mg}$ performed poorly in South-East Asia. It was significantly inferior in recurrence prevention compared with a low dose of primaquine (15 mg adults dose/day), and cure rates in South America were also disappointing $[97,99,100]$. The dose-finding study summarized in Fig. 10 indicates a relatively steep dose-response relationship over the adult dose range between 100 and $300 \mathrm{mg}$. Any shift to the right, such as would be associated with heavier patients, or larger hypnozoite burdens, receiving the fixed $300 \mathrm{mg}$ dose (as shown in Fig. 5), would be expected to reduce radical curative efficacy significantly (Fig. 11).

\section{Conclusions}

Slowly eliminated anti-malarial drugs delay, but usually do not eliminate Plasmodium vivax relapses. The blood stage activity of tafenoquine contributes to a significant delay in relapses becoming patent. The probability of relapse depends on many factors including the number of activatable hypnozoites in the liver and the exposure to, and activity of, the 8 -aminoquinoline radical cure treatment. Dose-response assessments indicate that the total dose of primaquine currently recommended by National malaria control programmes in most countries of South-East Asia and Oceania ( $3.5 \mathrm{mg}$ base $/ \mathrm{kg}$ ) is too low. While this dose might give high efficacy in patients with low hypnozoite burdens, it is not expected to give optimal cure rates in patients with heavier burdens. Clinical trials also indicate that the currently recommended dose of tafenoquine ( $300 \mathrm{mg}$ ) is too low. Higher doses of tafenoquine should be evaluated.

\section{Acknowledgements}

Special thanks to James Watson for statistical advice, to Dr. Cindy Chu and Dr. Bob Taylor for providing original data and to many colleagues in the Mahidol Oxford Research Unit and associated research programmes for their advice and support.

\section{Authors' contributions}

NJW conceived the ideas and wrote the paper. The author read and approved the final manuscript.

\section{Funding}

This study was funded by The Wellcome Trust (093956). For the purpose of open access the author has applied a CC-BY public copyright licence to any Author accepted manuscript version arising from this submission. NJW is a Wellcome Trust Principal Research Fellow.

\section{Availability of data and materials}

All data are from published studies.

\section{Declarations}

Ethics approval and consent to participate

Not applicable_-all clinical studies have been published.

\section{Competing interests}

The authors declare that they have no competing interests.

\section{Author details}

${ }^{1}$ Mahidol-Oxford Tropical Medicine Research Unit, Faculty of Tropical Medicine, Mahidol University, Bangkok 10400, Thailand. ${ }^{2}$ Centre for Tropical Medicine and Global Health, University of Oxford, Oxford, UK.

Received: 16 January 2021 Accepted: 12 March 2021

Published online: 21 March 2021

\section{References}

1. Anstey NM, Douglas NM, Poespoprodjo JR, Price RN. Plasmodium vivax: clinical spectrum, risk factors and pathogenesis. Adv Parasitol. 2012;80:151-201.

2. Dini S, Douglas NM, Poespoprodjo JR, Kenangalem E, Sugiarto P, Plumb ID, Price RN, Simpson JA. The risk of morbidity and mortality following recurrent malaria in Papua, Indonesia: a retrospective cohort study. BMC Med. 2020;18:e28

3. Recht J, Ashley EA, White NJ. Safety of 8-aminoquinoline antimalarial medicines. Geneva: World Health Organization; 2014.

4. Imwong M, Snounou G, Pukrittayakamee S, Tanomsing N, Kim JR, Nandy A, et al. Relapses of Plasmodium vivax infection usually result from activation of heterologous hypnozoites. J Infect Dis. 2007:95:927-33.

5. Chen N, Auliff A, Rieckmann K, Gatton M, Cheng Q. Relapses of Plasmodium vivax infection result from clonal hypnozoites activated at predetermined intervals. J Infect Dis. 2007;195:934-41.

6. Pybus BS, Sousa JC, Jin X, Ferguson JA, Christian RE, Barnhart R, et al. CYP450 phenotyping and accurate mass identification of metabolites of the 8-aminoquinoline, anti-malarial drug primaquine. Malar J. 2012;11:259.

7. Camarda G, Jirawatcharadech P, Priestley RS, Saif A, March S, Wong $\mathrm{MHL}$, et al. Antimalarial activity of primaquine operates via a two-step biochemical relay. Nat Commun. 2019;10:e3226.

8. Luxemburger C, van Vugt M, Jonathan S, McGready R, Looareesuwan $\mathrm{S}$, White NJ, et al. Treatment of vivax malaria in an endemic area on the western border of Thailand. Trans R Soc Trop Med Hyg. 1999:93:433-8.

9. Awab GR, Pukrittayakamee S, Imwong M, Dondorp AM, Woodrow CJ, Lee $S J$, et al. Dihydroartemisinin-piperaquine versus chloroquine to treat vivax malaria in Afghanistan: an open randomized, non-inferiority, trial. Malar J. 2010;9:105.

10. Phyo AP, Lwin KM, Price RN, Ashley EA, Russell B, Sriprawat K, et al. Dihydroartemisinin-piperaquine versus chloroquine in the treatment of Plasmodium vivax malaria in Thailand: a randomized controlled trial. Clin Infect Dis. 2011;53:977-84.

11. Kim JR, Nandy A, Maji AK, Addy M, Dondorp AM, Day NP, et al. Genotyping of Plasmodium vivax reveals both short and long latency relapse patterns in Kolkata. PLoS ONE. 2012;7:e39645.

12. Getachew S, Thriemer K, Auburn S, Abera A, Gadisa E, Aseffa A, et al. Chloroquine efficacy for Plasmodium vivax malaria treatment in southern Ethiopia. Malar J. 2015;14:525.

13. Awab GR, Imwong M, Bancone G, Jeeyapant A, Day NPJ, White NJ, et al. Chloroquine-primaquine versus chloroquine alone to treat vivax malaria in Afghanistan: an open randomized superiority trial. Am J Trop Med Hyg. 2017;97:1782-7.

14. Abreha T, Hwang J, Thriemer K, Tadesse Y, Girma S, Melaku Z, et al. Comparison of artemether-lumefantrine and chloroquine with and without primaquine for the treatment of Plasmodium vivax infection in Ethiopia: a randomized controlled trial. PLoS Med. 2017;14:e1002299.

15. Rijal KR, Adhikari B, Ghimire P, Banjara MR, Thakur GD, Hanboonkunupakarn B, et al. Efficacy of primaquine in preventing short and long latency Plasmodium vivax relapses in Nepal. J Infect Dis. 2019;220:448-56.

16. Chu CS, Phyo AP, Lwin KM, Win HH, San T, Aung AA, et al. Comparison of the cumulative efficacy and safety of chloroquine, artesunate, and chloroquine-primaquine in Plasmodium vivax malaria. Clin Infect Dis. 2018;67:1543-9.

17. Taylor WRJ, Thriemer K, von Seidlein L, Yuentrakul P, Assawariyathipat T, Assefa A, et al. Short-course primaquine for the radical cure of Plasmodium vivax malaria: a multicentre, randomised, placebo-controlled non-inferiority trial. Lancet. 2019;394:929-38. 
18. Silachamroon U, Krudsood S, Treeprasertsuk S, Wilairatana P, Chalearmrult K, Mint $H Y$, et al. Clinical trial of oral artesunate with or without high-dose primaquine for the treatment of vivax malaria in Thailand. Am J Trop Med Hyg. 2003;69:14-8.

19. Sinton JA, Smith S, Potinger D. Studies in malaria, with special reference to treatment. XII. Further researches into treatment of chronic benign tertian malaria with plasmoquine and quinine. Indian J Med Res. 1930;17:793.

20. RatcliffA, Siswantoro H, Kenangalem E, Maristela R, Wuwung RM, Laihad F, etal. Two fixed-dose artemisinin combinations for drug-resistant falciparum and vivax malaria in Papua, Indonesia: an open-label randomised comparison. Lancet. 2007;369:757-65.

21. Commons RJ, Simpson JA, Thriemer K, Abreha T, Adam I, Anstey NM, et al. The efficacy of dihydroartemisinin-piperaquine and artemether-lumefantrine with and without primaquine on Plasmodium vivax recurrence: a systematic review and individual patient data meta-analysis. PLoS Med. 2019;16:e1002928.

22. Hasugian AR, Purba HL, Kenangalem E, Wuwung RM, Ebsworth EP, Maristela $\mathrm{R}$, et al. Dihydroartemisinin-piperaquine versus artesunate-amodiaquine: superior efficacy and posttreatment prophylaxis against multidrug-resistant Plasmodium falciparum and Plasmodium vivax malaria. Clin Infect Dis. 2007:44:1067-74.

23. Pasaribu AP, Chokejindachai W, Sirivichayakul C, Tanomsing N, Chavez I, Tjitra $\mathrm{E}$, et al. A randomized comparison of dihydroartemisinin-piperaquine and artesunate-amodiaquine combined with primaquine for radical treatment of vivax malaria in Sumatera, Indonesia. J Infect Dis. 2013;208:1906-13.

24. Thuan PD, Ca NT, Toi PV, Nhien NT, Thanh NV, Anh ND, et al. A randomized comparison of chloroquine versus dihydroartemisinin-piperaquine for the treatment of Plasmodium vivax infection in Vietnam. Am JTrop Med Hyg. 2016;94:879-85.

25. Grigg MJ,William T, Menon J, Barber BE, Wilkes CS, Rajahram GS, etal. Efficacy of artesunate-mefloquine for chloroquine-resistant Plasmodium vivax malaria in Malaysia: an open-label, randomized, controlled trial. Clin Infect Dis. 2016;62:1403-11.

26. Chu CS, Phyo AP, Turner C, Win HH, Poe NP, Yotyingaphiram W, et al. Chloroquine versus dihydroartemisinin-piperaquine with standard high-dose primaquine given either for 7 days or 14 days in Plasmodium vivax malaria. Clin Infect Dis. 2019;68:1311-9.

27. Nelwan EJ, Ekawati LL, Tjahjono B, Setiabudy R, Sutanto I, Chand K, et al. Randomized trial of primaquine hypnozoitocidal efficacy when administered with artemisinin-combined blood schizontocides for radical cure of Plasmodium vivax in Indonesia. BMC Med. 2015;13:294.

28. Most H. Clinical trials of anti-malarial drugs. In: Internal medicine in WorldWar II, vol. 2. Infectious diseases. Office of the Surgeon General, Department of the Army. 1963:525-98.

29. Alving AS, Pullman TN, Craige B, Jones R, Whorton CM, Eichelberger L. The clinical trial of eighteen analogues of pamaquin (plasmochin) in vivax malaria (Chesson strain). J Clin Invest. 1948;27:34-45.

30. Craige B Jr, Alving AS, Jones R Jr, Whorton CM, Pullman TN, Eichelberger L. The Chesson strain of Plasmodium vivax malaria. I. Relationship between prepatent period, latent period and relapse rate. J Infect Dis. 1947;80:228-36.

31. White NJ. Determinants of relapse periodicity in Plasmodium vivax malaria. Malar J. 2011;10:297.

32. Garnham PCC. Relapses and latency in malaria. Protozoology. 1967;2:55-64.

33. Fairley NH. Sidelights on malaria in man obtained by subinoculation experiments. Trans R Soc Trop Med Hyg. 1947:40:621-76.

34. Boyd MF. The influence of sporozoite dosage in vivax malaria. Am JTrop Med. 1940;20:279-86

35. Coatney GR, Cooper WC, Young MD. Studies in human malaria. XXX. A summary of 204 sporozoite-induced infections with the Chesson strain of Plasmodium vivax. J Natl Malar Soc. 1950;9:381-96.

36. Schmidt LH. Compatibility of relapse patterns of Plasmodium cynomolgi infections in Rhesus monkeys with continuous cyclical development and hypnozoite concepts of relapse. Am JTrop Med Hyg. 1986;35:1077-99.

37. KitchenSF.Vivax malaria. In:Boyd MF,editor.Malariology, vol. 2. Philadephia:WB Saunders; 1949. p. 1027-45.

38. Luxemburger C, Thwai KL, White NJ, Webster HK, Kyle DE, Maelankirri L, et al. The epidemiology of malaria in a Karen population on the western border of Thailand. Trans R Soc Trop Med Hyg. 1996;90:105-11.

39. Looareesuwan S, White NJ, Chittamas S, Bunnag D, Harinasuta T. High rate of Plasmodium vivax relapse following treatment of falciparum malaria in Thailand. Lancet. 1987:2:10525.
40. Douglas NM, Nosten F, Ashley EA, Phaiphun L, van Vugt M, Singhasivanon P, et al. Plasmodium vivax recurrence following falciparum and mixed species malaria: risk factors and effect of anti-malarial kinetics. Clin Infect Dis. 2011;52:612-20.

41. Ashley EA, Phyo AP, Carrara VI, Tun KM, Nosten F, Smithuis F, et al. Plasmodium vivax relapse rates following falciparum malaria reflect previous transmission intensity. J Infect Dis. 2019;220:100-4.

42. Hossain MS, Commons RJ, Douglas NM, Thriemer K, Alemayehu BH, Amaratunga $C$, et al. The risk of Plasmodium vivax parasitaemia after P. falciparum malaria: an individual patient data meta- analysis from the WorldWide Antimalarial Resistance Network. PLoS Med. 2020;17:e1003393.

43. Imwong M, Nguyen TN, Tripura R, Peto TJ, Lee SJ, Lwin KM, et al. The epidemiology of subclinical malaria infections in South-East Asia: findings from cross-sectional surveys in Thailand-Myanmar border areas, Cambodia, and Vietnam. Malar J. 2015;14:381.

44. Bray RS, Garnham PC. The life-cycle of primate malaria parasites. Br Med Bull. 1982;38:117-22.

45. Rosenburg R, WirtzRA. An estimation of the number of sporozoites ejected by a feeding mosquito. Trans R Soc Trop Med Hyg. 1990;84:209-12.

46. PonnuduraiT,Lensen AHW, van-GemartGJA,BolmerMG,Meuwissen JH. Feeding behaviour and sporozoite ejection by infected Anopheles stephensi. Trans R Soc Trop Med Hyg. 1991;85:175-80,

47. Beier JC, Davis JR, Vaughan JA, Noden BH, Beier MS. Quantitation of Plasmodium falciparum sporozoites transmitted in vitro by experimentally infected Anopheles gambiae and Anopheles stephensi. Am J Trop Med Hyg. 1991:44:564-70.

48. Hill E, Amatuzio DS. Southwest Pacific vivax malaria: clinical features and observations concerning duration of clinical activity. Am J Trop Med Hyg. 1949;29:203-14.

49. Sutanto I,Tjahjono B, Basri H, Taylor WR, Putri FA, Meilia RA, et al. Randomized, open-label trial of primaquine against vivax malaria relapse in Indonesia. Antimicrob Agents Chemother. 2013;57:1128-35.

50. von Seidlein L, Peto TJ, Landier J, Nguyen TN, Tripura R, Phommasone K, et al. The impact of targeted malaria elimination with mass drug administrations on falciparum malaria in Southeast Asia: a cluster randomised trial. PLoS Med. 2019;16:e1002745.

51. Chaumeau V, Kajeechiwa L, Fustec B, Landier J, Naw Nyo S, Nay Hsel S, et al. Contribution of asymptomatic Plasmodium infections to the transmission of malaria in Kayin State, Myanmar. J Infect Dis. 2019;219:1499-509.

52. Commons RJ, Simpson JA, Thriemer K, Humphreys GS, Abreha T, Alemu SG, et al. The effect of chloroquine dose and primaquine on Plasmodium vivax recurrence: a WorldWide Antimalarial Resistance Network systematic review and individual patient pooled meta-analysis. Lancet Infect Dis. 2018;18:1025-34.

53. Commons RJ, Simpson JA, Watson J, White NJ, Price RN. Estimating the proportion of Plasmodium vivax recurrences caused by relapse: a systematic review and meta-analysis. Am JTrop Med Hyg. 2020;103:1094-9.

54. Schmidt LH, Fradkin R, Vaughan D, Rasco J. Radical cure of infections with Plasmodium cynomolgi: a function of total 8-aminoquinoline dose. Am J Trop Med Hyg. 1977;26:1116-28.

55. Schmidt LH, Cramer DV, Rossan RN, Harrison J. The characteristics of Plasmodium cynomolgi infections in various old world primates. Am J Trop Med Hyg. 1977:26:356-72.

56. Pukrittayakamee S, Chantra A, Simpson JA, Vanijanonta S, Clemens R, Looareesuwan $\mathrm{S}$, et al. Therapeutic responses to different antimalarial drugs in vivax malaria. Antimicrob Agents Chemother. 2000;44:1680-5.

57. White NJ. The assessment of antimalarial drug efficacy. Trends Parasitol. 2002:18:458-64.

58. Watson J, Chu CS, Tarning J, White NJ. Characterizing blood-stage antimalarial drug MIC values in vivo using reinfection patterns. Antimicrob Agents Chemother. 2018;62:e02476-17.

59. White NJ, Watson JA, Hoglund RM, Chan XHS, Cheah PY, Tarning J. COVID-19 prevention and treatment: a critical analysis of chloroquine and hydroxychloroquine clinical pharmacology. PLoS Med. 2020;17:e1003252.

60. Höglund R, Moussavi Y, Ruengweerayut R, Cheomung A, Äbelö A, NaBangchang K. Population pharmacokinetics of a three-day chloroquine treatment in patients with Plasmodium vivax infection on the Thai-Myanmar border. Malar J. 2016:15:129.

61. Taylor WR, Doan HN, Nguyen DT, Tran TU, Fryauff DJ, Gómez-Saladín E, et al. Assessing drug sensitivity of Plasmodium vivax to halofantrine or choroquine 
in southern, central Vietnam using an extended 28-day in vivo test and polymerase chain reaction genotyping. Am J Trop Med Hyg. 2000;62:693-7.

62. Jeffery GM. Relapses with Chesson strain Plasmodium vivax following treatment with chloroquine. Am J Trop Med Hyg. 1956;5:1-13.

63. Baird JK, Leksana B, Masbar S, Fryauff DJ, Sutanihardja M, Wignall FS, Hoffman SL. Diagnosis of resistance to chloroquine by Plasmodium vivax: timing of recurrence and whole blood chloroquine levels. Am JTrop Med Hyg. 1997;56:621-6.

64. Baird JK. Chloroquine resistance in Plasmodium vivax. Antimicrob Agents Chemother. 2004;48:4075-83.

65. Russell BM, Udomsangpetch R, Rieckmann KH, Kotecka BM, Coleman RE Sattabongkot J. Simple in vitro assay for determining the sensitivity of Plasmodium vivax isolates from fresh human blood to antimalarials in areas where P. vivax is endemic. Antimicrob Agents Chemother. 2003;47:170-3.

66. Commons RJ, Simpson JA, Thriemer K, Chu CS, Douglas NM, Abreha T, et al. The haematological consequences of Plasmodium vivax malaria after chloroquine treatment with and without primaquine: a WorldWide AntimalarialResistance Network systematic review and individual patient data meta-analysis. BMC Med. 2019;17:151.

67. Taylor WR, Widjaja H, Richie TL, Basri H, Ohrt C, Tjitra, et al. Chloroquine/doxycycline combination versus chloroquine alone, and doxycycline alone for the treatment of Plasmodium falciparum and Plasmodium vivax malaria in northeastern Irian Jaya, Indonesia. Am J Trop Med Hyg. 2001;64:223-8.

68. Ratcliff A, Siswantoro H, Kenangalem E, Wuwung M, Brockman A, Edstein MD et al. Therapeutic response of multidrug-resistant Plasmodium falciparum and $P$. vivax to chloroquine and sulfadoxine-pyrimethamine in southern Papua, Indonesia. Trans R Soc Trop Med Hyg. 2007;101:351-9.

69. Sutanto I, Endawati D, Ling LH, Laihad F, Setiabudy R, Baird JK. Evaluation of chloroquine therapy for vivax and falciparum malaria in southern Sumatra, western Indonesia. Malar J. 2010;9:52.

70. John GK, Douglas NM, von Seidlein L, Nosten F, Baird JK, White NJ, et al. Primaquine radical cure of Plasmodium vivax: a critical review of the literature. Malar J. 2012;11:280.

71. WHO. Guidelines for the treatment of malaria. Geneva:World Health Organization; 2015.

72. Pukrittayakamee S, Imwong M, Chotivanich K, Singhasivanon P, Day NP, White NJ. A comparison of two short-course primaquine regimens for the treatment and radical cure of Plasmodium vivax malaria in Thailand. Am JTrop Med Hyg. 2010;82:542-7.

73. Edgcomb JH, Arnold J, Yount EH, Alving AS, Eichelberger L, Jeffery G, et al. Primaquine, SN 13272, a new curative agent in vivax malaria: a preliminary report. J Natl Malar Soc. 1950;9:285-92.

74. Robinson DH, Di Lorenzo A, Marx RL, Simmons IH, Alving AS, Hankey DD, et al. Korean vivax malaria. II. Curative treatment with pamaquine and primaquine. Am JTrop Med Hyg. 1953;2:970-6.

75. CooperWC, Myatt AV, HernandezT, Jeffery GM, Coatney GR. Studies in human malaria. XXXI. Comparison of primaquine, isopentaquine, $\mathrm{SN}-3883$, and pamaquine as curative agents against Chesson strain vivax malaria. Am J Trop Med Hyg. 1953;2:949-57.

76. Arnold J, Alving AS, Clayman CB. Induced primaquine resistance in vivax malaria. Trans R Soc Trop Med Hyg. 1961;55:345-50.

77. Pukrittayakamee S, Vanijanonta S, Chantra A, Clemens R, White NJ. Blood stage antimalarial efficacy of primaquine in Plasmodium vivax malaria. J Infect Dis. 1994;169:932-5.

78. Alving AS, Arnold J, Hockwald RS, Clayman CB, Dern RJ, Beutler E, et al. Potentiation of the curative action of primaquine in vivax malaria by quinine and chloroquine. J Lab Clin Med. 1955;46:301-6.

79. Schmidt LH. Comparative efficacies of quinine and chloroquine as companions to primaquine in a curative drug regimen. Am JTrop Med Hyg. 1981;30:20-5.

80. Baird JK. 8-Aminoquinoline therapy for latent malaria. Clin Microbiol Rev. 2019:32:e00011-19.

81. Baird JK, Basri H, Subianto B, Fryauff DJ, McElroy PD, Leksana B, et al. Treatment of chloroquine-resistant Plasmodium vivax with chloroquine and primaquine or halofantrine. J Infect Dis. 1995;171:1678-82.

82. Pukrittayakamee S, Imwong M, Singhasivanon P, Stepniewska K, Day NJ, White NJ. Effects of different antimalarial drugs on gametocyte carriage in P. vivax malaria. Am J Trop Med Hyg. 2008;79:378-84.
83. Kho S. Role of the spleen, platelets and neutrophils in human malaria. Ph.D thesis, Charles Darwin University, Darwin, NT, Australia.

84. Taylor AR, Watson JA, Chu CS, Puaprasert K, Duanguppama J, Day NPJ, et al. Resolving the cause of recurrent Plasmodium vivax malaria probabilistically. Nat Commun. 2019;10:e5595.

85. Gonçalves BP, Pett H, Tiono AB, Murry D, Sirima SB, Niemi M, et al. Age, weight, and CYP2D6 genotype are major determinants of primaquine pharmacokinetics in African children. Antimicrob Agents Chemother. 2017:61:e02590-16.

86. Peters W, Robinson BL, Milhous WK. The chemotherapy of rodent malaria. LI. Studies on a new 8-aminoquinoline, WR 238,605. Ann Trop Med Parasitol. 1993;87:547-52.

87. Brueckner RP, Lasseter KC, Lin ET, Schuster BG. First-time-in humans safety and pharmacokinetics ofWR 238605, a new antimalarial. Am J Trop Med Hyg. 1988;58:645-9.

88. Brueckner RP, Coster T, Wesche DL, Shmuklarsky M, Schuster BG. Prophylaxis of Plasmodium falciparum infection in a human challenge model with WR 238605, a new 8-aminoquinoline antimalarial. Antimicrob Agents Chemother. 1998;42:1293-4.

89. Quashie NB, Duah NO, Abuaku B, Quaye L, Ayanful-Torgby R, Akwoviah GA, et al. A SYBR Green 1-based in vitro test of susceptibility of Ghanaian Plasmodium falciparum clinical isolates to a panel of anti-malarial drugs. Malar J. 2013;12:450

90. Dow G, Smith B. The blood schizonticidal activity of tafenoquine makes an essential contribution to its prophylactic efficacy in nonimmune subjects at the intended dose (200 mg). Malar J. 2017;16:209.

91. St Jean PL, Koh GCKW, Breton JJ, Espino FEJ, Hien TT, Krudsood S, et al. Pharmacogenetic assessment of tafenoquine efficacy in patients with Plasmodium vivax malaria. Pharmacogenet Genomics. 2020;30:161-5.

92. St Jean PL, Xue Z, Carter N, Koh GC, Duparc S, Taylor M, et al. Tafenoquine treatment of Plasmodium vivax malaria: suggestive evidence that CYP2D6 reduced metabolism is not associated with relapse in the Phase $2 \mathrm{~b}$ DETECTIVE trial. Malar J. 2016;15:97.

93. Gural N, Mancio-Silva L, Miller AB, Galstian A, Butty VL, Levine SS, et al. In vitro culture, drug sensitivity, and transcriptome of Plasmodium vivax hypnozoites. Cell Host Microbe. 2018;23:395-406.e4

94. Roth A, Maher SP, Conway AJ, Ubalee R, Chaumeau V, Andolina C, et al. A comprehensive model for assessment of liver stage therapies targeting Plasmodium vivax and Plasmodium falciparum. Nat Commun. 2018;9:1837.

95. Dow GS, Liu J, Lin G, Hetzell B, Thieling S, McCarthy WF, et al. Summary of antimalarial prophylactic efficacy of tafenoquine from three placebo-controlled studies of residents of malaria-endemic countries. Malar J. 2015;14:473.

96. Dow GS, Gettayacamin M, Hansukjariya P, Imerbsin R, Komcharoen S, Sattabongkot J, et al. Radical curative efficacy of tafenoquine combination regimens in Plasmodium cynomolgi-infected Rhesus monkeys (Macaca mulatta). Malar J. 2011;10:212.

97. Llanos-Cuentas A, Lacerda MVG, Hien TT,Vélez ID, Namaik-LarpC, Chu CS, etal. Tafenoquine versus primaquine to prevent relapse of Plasmodium vivax malaria. N Engl J Med. 2019;380:229-41.

98. Llanos-Cuentas A, Lacerda MV, Rueangweerayut R, Krudsood S, Gupta SK, Kochar SK, et al. Tafenoquine plus chloroquine for the treatment and relapse prevention of Plasmodium vivax malaria (DETECTIVE): a multicentre, double-blind, randomised, phase $2 \mathrm{~b}$ dose-selection study. Lancet. 2014;383:1049-58.

99. Lacerda MVG, Llanos-Cuentas A, Krudsood S, Lon C, Saunders DL, Mohammed $\mathrm{R}$, et al. Single-dose tafenoquine to prevent relapse of Plasmodium vivax malaria. N Engl J Med. 2019;380:215-28.

100. BeckHP,Wampfler R, Carter N, Koh G, Osorio L, Rueangweerayut R, etal. Estimation of the antirelapse efficacy of tafenoquine, using Plasmodium vivax genotyping. J Infect Dis. 2016;213:794-9.

\section{Publisher's note}

Springer Nature remains neutral with regard to jurisdictional claims in published maps and institutional affiliations. 